\title{
PARA ALÉM DA AVENIDA: O CARNAVAL DE CRUZ ALTA À LUZ DA FOLKCOMUNICAÇÃOO
}

\author{
Fabiane da Verissimo ${ }^{\text {ii }}$ \\ Marcela Guimarães e Silva ${ }^{\text {iii }}$
}

\begin{abstract}
Resumo:
$\mathrm{O}$ artigo tem como objetivo analisar o espaço dado ao carnaval, na mídia impressa, na cidade de Cruz Alta. Para tanto, adotou-se a metodologia de estudo à luz da folkcomunicação. Conclui-se que o carnaval ainda é visto como um momento de festa e que há um desconhecimento social do evento, enquanto formador de uma identidade cultural comum àqueles que participam da comunidade, da escola de samba.
\end{abstract}

\section{Palavras-chave:}

Identidade cultural; mídia impressa; manifestação popular

\section{Resumen:}

El presente artículo tiene por objetivo analizar el espacio dado al carnaval, en los medios de comunicación impresos, en la ciudad de Cruz Alta. Para ello, se adoptó la metodología de estudio a la luz de la folk comunicación (comunicación popular). Se concluye que al carnaval todavía se lo ve como un momento de fiesta y que hay un desconocimiento social del evento, como formador de una identidad cultural común a aquellos que participan en la comunidad de la escuela de samba.

\section{Palabras clave:}

Identidad cultural; medios de comunicación impresa; manifestación popular.

\begin{abstract}
:
The goal of this article is to analyse the space given to Carnival, in the press midia, in the city of Cruz Alta. For this it was adopted the methodology of studying this event under folkcommunication. It was concluded that carnival still is that special moment of party and that there is a social unknowing of the event regarding to a cultural identity, concerning to those who participate of the community, samba schools.
\end{abstract}

Key words:

Cultural identity; press midia; popular public demonstration.

\section{Introdução}

O presente estudo tem origem da pesquisa realizada para projeto de pesquisa "Carnaval: palco de manifestação da cultura popular e de reafirmação identitária de um grupo", da Universidade de Cruz Alta e tem objetivo analisar o espaço ocupado pelo movimento cultural na mídia à luz da teoria de Luiz Beltrão, a folkcomunicação, sobretudo na linha preconizada por José Marque de Melo.

Inicialmente elaborou-se junto às comunidades carnavalescas de Cruz Alta o resgate histórico do carnaval, identificando a função exercida na vida das pessoas e de que modo o trabalho desenvolvido no interior das comunidades é percebido e valorizado, tanto do ponto de vista de quem participa, quanto da mídia. 
Para isso adotou-se a mesma metodologia proposta por Marques de Melo na pesquisa que buscou resgatar as imagens projetadas pela mídia durante a celebração do "Carnaval dos 500 anos de Descobrimento do Brasil". Com base no método adotado foram analisadas as edições do Jornal Diário Serrano, único jornal diário do município, para verificar a visibilidade e a linha que o jornal adotou para noticiar e divulgar o carnaval, considerado atualmente um dos maiores eventos de Cruz Alta.

Desta forma este estudo inicialmente contextualiza o carnaval historicamente, destacando a sua função social e econômica para as comunidades, para então analisar o enfoque trabalhado pela mídia impressa, nos permitindo identificar a necessidade de abordar o evento sob outras perspectivas pela importância assumida para o público envolvido e por caracterizar-se como um movimento de reafirmação identitária e emancipatório para as pessoas.

\section{O carnaval em Cruz Alta}

Com mais de 60 anos o carnaval de Cruz Alta é um movimento popular que sempre se destacou nas manifestações alusivas a data por meio de bailes em clubes, desfiles de rua e rodas de samba. Inicialmente foi marcado por blocos carnavalescos como Ases de Ouro e Filhos da Lua, que na época embalavam os bailes e apresentações pelas ruas com marchinhas e batucadas. Estes mesmos blocos foram compostos por personalidades do samba cruzaltense e deram origem as mais tradicionais escolas de samba do município.

As duas primeiras escolas de Cruz Alta foram: Grêmio Recreativo de Escola de Samba Unidos do Beco e Grêmio Recreativo de Escola de Samba de Unidos de São José, porém outras foram surgindo, tais como: Acadêmicos do Sol, Imperatriz da Zona Norte e Gaviões da Ferrô, e que permanecem até hoje. Mocidade Independente de São Miguel, Unidos de Vila Brenner, Unidos de Vila Lizabel e AMIMO - Associação Mocidade Independente da Montanha de Ouro surgiram logo depois e que por falta de mobilização das comunidades deixaram de existir, ou pelo menos abandonaram os tradicionais desfiles na avenida.

O carnaval de Cruz Alta também é marcado pela formação de dois grupos. O primeiro formado pela elite, que na época era responsável pelos bailes aristocráticos e desfiles pomposos em carro aberto pelas principais ruas da cidade, onde jovens moças desfilavam para a população, que envaidecida atirava confetes e serpentinas para saudá-las. O segundo, pela classe mais popular, constituída em sua maioria por grupos familiares, 
descendentes de negros, comunidades sambistas, que enalteciam as raízes do samba e embalavam com alegria o povo cruzaltense. Entretanto após longos anos de mudanças políticas e econômicas, algumas barreiras sumiram, e a maior festa popular brasileira se democratizou, sendo um espaço de convergência entre diferentes classes sociais, raciais e religiosas.

Com o passar dos anos, outras agremiações carnavalescas surgiram, e com o aprimoramento de seus trabalhos elevaram o carnaval de Cruz Alta a um dos melhores do interior, e o $4^{\circ}$ melhor do Estado. A cada ano o carnaval vem se transformando e inovando o trabalho das cinco escolas existentes, que buscam fazer o melhor para qualificar ainda mais a festa. Os bailes realizados nos clubes permanecem, porém com outras características, não mais aquelas do passado.

Em 1990, o carnaval de Cruz Alta sofreu modificações com a fundação da Escola Acadêmica do Sol a qual trouxe para a avenida, em 1992, uma proposta de desfile semelhante aos adotados pelas escolas tradicionais do Rio de Janeiro, e que passou a ser uma referência para as escolas. A partir deste momento as demais adotaram a mesma proposta e o carnaval passou a exigir a participação efetiva de seus componentes e isso estabeleceu uma relação de comprometimento entre a escola e seus componentes.

Atualmente as comunidades carnavalescas demonstram muito profissionalismo e criatividade para expressar suas idéias, e desta forma as diretorias das escolas acreditam estar desenvolvendo um trabalho social, cultural e econômico junto às comunidades. As escolas de samba têm um papel fundamental na formação da identidade cultural de suas comunidades. Elas proporcionam um espaço de convivência social que contribui na formação do caráter e na qualificação de suas comunidades. Este espaço torna-se parte integrante da vida das pessoas, onde as mesmas tomam para si a responsabilidade de gerir e de mantê-las.

Além disso, as escolas de samba são palco de manifestação para diversos artistas anônimos que, na época do carnaval, exercem suas expressividades. Também é espaço de lazer e entretenimento para quem não pode usufruir outros locais de divertimento, e para uma parcela da população, contribui economicamente quando proporciona a geração de trabalho e renda.

Para as pessoas externas ao dia-a-dia de uma escola de samba, o carnaval não possa de encantamento e magia. Um momento lúdico onde o espetáculo e a fantasia possibilitam 
a inversão de papéis. Empregados e patrões mudam de lugar, homens e mulheres trocam de gênero, enfim tudo é permitido em nome da alegria. O carnaval é o espaço ideal para mudar de lugar, alterar a posição na estrutura social. "De realmente inverter o mundo em direção a alegria, à abundância, á liberdade e, sobretudo, à igualdade de todos perante a sociedade". (DAMATTA, 1997, p. 78).

O caráter cultural da festa é evidente, uma vez que está inserida num contexto maior e mais complexo, envolvendo diferentes áreas - religião, música, dança, artes plásticas, visuais e cênicas; além é claro, de evocar o papel social de envolvimento das comunidades e estímulo ao aprimoramento e desenvolvimento da auto-estima da população, em diferentes momentos.

Segundo NERY (2008) "as escolas de samba operam em dois momentos diferentes, seguindo um ciclo anual bem demarcado. Um é o desfile de avenida e o outro é o resto do ano em que as escolas preparam a festa", o que gera para aqueles que desconhecem o evento, uma impressão de um espetáculo e não de uma manifestação cultural de um grupo social organizado.

A maioria das pessoas não sabe como funcionam as engrenagens de uma escola de samba, muito menos a sua importância para o desenvolvimento social e econômico de uma cidade. Muitos até criticam, na tentativa de atrelar o carnaval e as escolas de samba ao desperdício de recursos públicos, e a confrontos de ordem religiosa.

O poder público tem um papel fundamental, pois ele subsidia a realização do mesmo dispondo de recursos financeiros e infra-estrutura para as escolas durante o período do carnaval mantendo a consolidação do evento todos os anos. As escolas também buscam alternativas de se autofinanciar, não ficando somente dependentes ao poder público. Mesmo assim, o incentivo das administrações na realização da maior festa popular brasileira garante a manutenção e a preservação da identidade cultural da comunidade com o carnaval.

O carnaval para a religião Católica é uma comemoração que faz parte de seus festejos e que antecede os preparativos para a Quaresma. Durante quarenta dias católicos se preparam espiritualmente para a chegada da Páscoa - celebração importante para os fieis católicos. A "Quarta-feira de Cinzas" dia de penitência e de perdão marca o fim do carnaval e o início do período da Quaresma. Portanto, o caráter religioso do evento também faz parte da cultura local, em virtude do número significativo de fiéis católicos que participam de uma forma ou de outra, das festas carnavalescas. 
Por tudo isso, o carnaval pode ser entendido como um movimento da cultura popular que pelos elementos estruturais e pela trajetória, agrega atores socias e os mobiliza a trabalhar e a participar da vida das escolas. E, ultimamente é visto como um referencial e uma forma de reconhecimento do grupo, o que muitas vezes no conjunto da sociedade, isto não é possível.

Um dos fatores que contribuem para essa manifestação popular é o apoio midiático, uma vez que mobilizam indivíduos e multidões a aderirem a prática social e econômica dos festejos carnavalesco, sejam eles nas praças, ruas ou clubes. O papel dos meios de comunicação de massa na construção da identidade cultural é, certamente, relevante. $\mathrm{O}$ jornal, a televisão e o rádio são formadores de opinião e agentes de transformação que vêem na cultura popular a possibilidade de influenciar os modos de ser, pensar, sentir e agir de um grupo social.

O carnaval brasileiro é uma festa popular com características regionais distintas, no Rio de Janeiro, São Paulo e Porto Alegre o carnaval de rua cultiva a tradição. No Recife e Olinda o ritmo do carnaval é o frevo e o maracatu. Na Bahia os trios-elétricos é que embalam os foliões. O samba, o frevo e as marchas são os principais ritmos que animam o carnaval brasileiro e também são responsáveis pelo aumento de turistas e fomento a cultura nessas regiões. Entretanto o que prevalece, na mídia, em especial a televisiva, é o modelo carioca das escolas de samba, que explora o evento enquanto manifestação popular cultural brasileira.

Considerada a maior festa popular da região, o carnaval em Cruz Alta reúne elementos que fazem do município referência estadual em festas momescas. Ainda que não tenha atingido a mesma grandiosidade e visibilidade dos carnavais do Rio de Janeiro e São Paulo, tem sua importância reconhecida no estado do Rio Grande do Sul, e a cada ano que passa o carnaval de Cruz Alta vem firmando seu espaço enquanto manifestação popular e organização social.

Mas para a mídia cruzaltense, sobretudo a impressa, que importância tem o carnaval? O evento é considerado uma manifestação popular cultural? Participa efetivamente das pautas diárias no período momesco? Contribui para a formação da identidade cultural dos integrantes das comunidades carnavalescas? Essas são algumas questões que este estudo busca responder.

\section{Escolhas Metodológicas}


A metodologia base desta pesquisa tem origem na teoria proposta por Luiz Beltrão em sua tese de doutorado na década de 60, em que o autor define o conceito de folkcomunicação como "os processos de intercâmbio de informações e manifestações de opiniões, idéias e atitudes da massa, através de agentes e meios ligados diretamente ou indiretamente ao folclore" (BELTRÃO apud Carvalho, 2008, p. 11).

Já na década de 80 com a evolução dos estudos na área, Beltrão busca através da folkcomunicação identificar como os grupos marginalizados se comunicam sem utilizar-se dos meios de comunicação de massa, como criam mecanismos de comunicação e transmitem suas mensagens.

Entretanto, de acordo com CARVALHO (2008) a partir da teoria da folkcomunicação de Beltrão outros estudiosos como Antônio Hohlfeldt, Joseph Luyten, Roberto Benjamin e José Marques de Melo buscaram verificar a aplicabilidade da teoria na prática avaliando as formas de comunicação entre os grupos populares questionando a teoria da folkcomunicação.

Neste sentido HOHLFEDT define a folkcomunicação como:

O estudo dos procedimentos comunicacionais pelos quais as manifestações da cultura popular ou do folclore se expandem, se socializam, convivem com outras cadeias comunicacionais, sofrem modificações por influência da comunicação massificada e industrializada, ou se modificam quando apropriadas por tais complexos (apud Carvalho, 2008, p. 111).

Nesta perspectiva passou-se a observar os meios de comunicação de massa e como os mesmos abordavam os movimentos da cultura popular, ou seja, ocorreu o processo inverso, as fontes da cultura popular passaram a alimentar a mídia de massa. Foi também a partir dos estudos de Beltrão que Marques de Melo desenvolveu uma pesquisa com o objetivo de resgatar as imagens projetadas pela mídia do "Carnaval dos 500 anos de Descobrimento do Brasil” (MELO, 2008, p. 71).

Para realização da pesquisa o autor definiu como amostra, jornais brasileiros e de outros países, contanto com a participação de vários estudiosos, além disso, definiu duas categorias comunicacionais (jornalismo e publicidade), quantificando as informações para posteriormente analisadas de acordo com três níveis de conteúdo: eixo temáticos, estratégias comunicacionais e referentes culturais (MELO, 2008).

O estudo desenvolvido por Marque de Melo serviu de referência para a presente pesquisa, porém optamos por escolher apenas uma amostra midiática, o Jornal Diário Serrano, visto que é o único jornal diário da cidade. O período estudado compreende aos 
meses de outubro de 2008 a fevereiro de 2009 e teve por objetivo identificar a abordagem dada pela mídia impressa, uma das maiores formadoras de opinião do município, ao carnaval de Cruz Alta.

Para a realização da pesquisa, a equipe do projeto sentiu a necessidade de participar das rotinas produtivas das escolas de samba de Cruz Alta, do princípio ao fim. Acompanhou reuniões, ensaios, festas, visitou os ateliês e barracões e finalmente, prestigiou o desfile na avenida. Isso nos permitiu entender a importância que o evento tem, em todo o seu percurso, na vida das comunidades.

Paralelo a isso todos os exemplares do jornal, foram sendo arquivados, separados por mês. No final da amostra cada edição foi lida cuidadosamente com o objetivo de identificar as matérias referentes ao tema Carnaval. Cada uma delas foi medida em $\mathrm{cm} / \mathrm{col}$ (centímetro-coluna) e depois transformada em porcentagem para obter a proporção do espaço editorial dedicado ao carnaval em toda a amostra, deste modo, foi possível verificar o grau de importância do evento, para a mídia local. A etapa seguinte procurou mensurar o espaço ocupado por categorias comunicacionais - jornalísticas e publicitárias e depois temáticas - rua, clube, saúde..., a fim de identificar os assuntos abordados relacionados ao carnaval. Depois foi observado nos registros, a composição verbal/visual das matérias, isso possibilitou identificar a articulação entre texto e imagem.

Posteriormente a equipe buscou classificar e analisar as matérias por categorias comunicacionais - jornalismo (informativo, opinativo, interpretativo) e publicidade (anúncios e matérias pagas de produtos, serviços, instituições). Após por eixos temáticos (tradição/inovação, espaço/tempo e público/privado) e estratégias comunicacionais (informação/persuasão e texto/ilustração).

\section{Um breve histórico do Diário Serrano}

O Diário Serrano foi fundado em 20 de fevereiro de 1939 e, integra o Grupo Planalto Médio desde 1970 sendo o único jornal diário da cidade, com 70 anos de atividades prestadas à comunidade cruzaltense, é considerado uma referência para a população.

O primeiro exemplar do Diário Serrano foi apresentado à comunidade cruz-altense trazendo na capa os nomes dos diretores Eurides de Castro e Juarez Illa Font - fundadores do jornal. Em 1951, Prudêncio Rocha adquiriu o jornal Diário Serrano, tendo como diretores, Prudêncio Rocha e Américo Dal Forno. Em 1978, novamente o jornal troca de dono, passando para Riograndino Abreu, que até hoje está a frente da Empresa Jornalística 
do Planalto Médio.

O jornal Diário Serrano é um dos mais tradicionais veículos de comunicação do interior do Rio Grande do Sul e foi pioneiro na aquisição de uma rotativa off-set, no ano de 1974. Com essas instalações, foi o primeiro jornal diário a obter esse processo no interior do Estado do Rio Grande do Sul, o que só havia em Porto Alegre por meio da Zero Hora.

A partir deste investimento consolidou a legenda da empresa interiorana, com equipamentos modernos e uma rotativa em off-set que foi acionada no dia de sua inauguração. A primeira edição da rotativa tinha 60 páginas, divididas em 4 cadernos. Curiosidade: "Anastácia" era o nome pela qual era chamada a máquina plana, na qual foi impresso o Diário Serrano durante uns 18 anos.

Hoje com 70 anos de circulação diária, ininterrupta abrange além de Cruz Alta, quatro municípios da região Noroeste do Estado: Boa Vista do Incra, Boa Vista do Cadeado, Pejuçara e Fortaleza dos Valos.

Com uma tiragem crescente - sendo 90\% distribuído em forma de assinaturas - é um jornal essencialmente comunitário, defendendo assuntos de interesse dos municípios onde realiza cobertura.

De acordo com pesquisas realizadas, 25.500 pessoas lêem o jornal Diário Serrano na região em que se propõe a atingir. Em termos proporcionais, é o sétimo jornal mais lido do Estado do Rio Grande do Sul.

A base do jornal Diário Serrano está alicerçada no profissionalismo e na ética, e os veículos de comunicação do Grupo Planalto Médio contam com equipes qualificadas e redação totalmente informatizada. Um dos principais objetivos da empresa seja nas emissoras de rádio ou nos jornais, é levar até o público, informações valorizando as comunidades locais e incentivando o desenvolvimento. O jornal Diário Serrano esteve a frente de importantes conquistas, que marcaram a história da cidade nos últimos 70 anos.

Ao apontar o papel desenvolvido pelo jornal Diário Serrano e a sua importância para a população de Cruz Alta e região, escolheu-se o referido veículo como objeto de análise para identificar o modo pela qual a população conhece e percebe o carnaval local. Também busca verificar o espaço dado pelo jornal a um evento considerado um dos maiores da cidade e que representa a manifestação da cultura popular e retrata um pouco da história do povo cruzaltense.

\section{Em busca de algumas evidências}


Para alcançar tais objetivos optou-se por realizar, num primeiro momento, uma pesquisa quantitativa que foi organizada em quatro etapas: a primeira permitiu contabilizar em números e porcentagens os registros jornalísticos e publicitários, bem como o espaço dedicado ao tema Carnaval nas edições de outubro a fevereiro de 2008.

\begin{tabular}{|c|c|c|c|c|c|c|}
\hline Mês & Outubro & Novembro & Dezembro & Janeiro & Fevereiro & Total \\
\hline $\begin{array}{c}\text { Registros } \\
\text { jornalísticos }\end{array}$ & 01 & 02 & 08 & 33 & 50 & $\mathbf{9 4}$ \\
\hline $\begin{array}{c}\text { Registros } \\
\text { publicitários }\end{array}$ & 01 & 00 & 00 & 02 & 24 & $\mathbf{2 7}$ \\
\hline Total & $\mathbf{0 2}$ & $\mathbf{0 2}$ & $\mathbf{0 8}$ & $\mathbf{3 5}$ & $\mathbf{7 4}$ & $\mathbf{1 2 1}$ \\
\hline
\end{tabular}

Tabela 1 - Número de registros jornalísticos e publicitários.

\begin{tabular}{|c|c|c|c|c|c|c|}
\hline Mês & Outubro & Novembro & Dezembro & Janeiro & Fevereiro & Total \\
\hline $\begin{array}{c}\text { Registros } \\
\text { jornalísticos }\end{array}$ & $50 \%$ & $100 \%$ & $100 \%$ & $94 \%$ & $67,6 \%$ & $\mathbf{7 7 , 6 \%}$ \\
\hline $\begin{array}{c}\text { Registros } \\
\text { publicitários }\end{array}$ & $50 \%$ & 00 & 00 & $06 \%$ & $32,4 \%$ & $\mathbf{2 2 , 4 \%}$ \\
\hline Total & $100 \%$ & $100 \%$ & $100 \%$ & $100 \%$ & $100 \%$ & $\mathbf{1 0 0 \%}$ \\
\hline
\end{tabular}

Tabela 2 - Porcentagem de registros jornalísticos e publicitários.

\begin{tabular}{|c|c|c|c|c|c|c|}
\hline Mês & Outubro & Novembro & Dezembro & Janeiro & Fevereiro & Total \\
\hline $\begin{array}{c}\text { Espaço } \\
\text { ocupado entre } \\
\text { Jornalismo e } \\
\text { Publicidade }\end{array}$ & $0,28 \%$ & $0,06 \%$ & $0,30 \%$ & $3,1 \%$ & $8,9 \%$ & $\mathbf{1 2 , 6 4}$ \\
\hline
\end{tabular}

Tabela 3 - Espaço ocupado pelo tema Carnaval entre jornalismo e publicidade.

Ao analisar as tabelas acima se pode constatar que o Carnaval é abordado somente nos meses de Janeiro e Fevereiro, embora o evento começa a ser pensado, idealizado, organizado, pelo menos seis meses antes do dia oficial. Quanto ao espaço ocupado, entre jornalismo e publicidade, o percentual é baixo considerando a importância que o evento tem para a comunidade local. Para se ter uma idéia em toda amostra somente $12,64 \%$ do espaço é dedicado ao assunto. Esses dados denotam que o Carnaval mesmo sendo considerado a maior festa popular da cidade de Cruz Alta é pouco explorado pela mídia. 
Após a análise empírica de aproximadamente 110 exemplares, desses 20 são do mês de outubro, 24 do mês de novembro, 23 do mês de dezembro, 23 do mês de janeiro e 20 do mês de fevereiro foram encontrados 121 registros relacionados ao tema, 94 jornalísticos e 27 publicitários. É importante destacar que no mês de fevereiro o Carnaval foi pauta em todos os exemplares e manchete de capa, em 12 deles.

A segunda etapa da pesquisa quantitativa consistiu em separar os registros por categorias temáticas a fim de verificar o enfoque que o veículo dá ao tema Carnaval. Foram elencadas 06 Categorias de análise que permitiram desenvolver um estudo dos assuntos abordados pelo jornal. São elas: Carnaval cujas matérias vertem sobre concursos de fantasias, rainhas e intermunicipal, anúncios, programação e avisos de utilidade pública. Carnaval de Rua - programação, comercialização de mesas e ingressos, divulgação, escolas de samba, anúncios e matérias pagas. Carnaval de Clube matérias sobre as pessoas que freqüentam os clubes: Arranca, Internacional e Grêmio dos Subtenentes. Carnaval e Saúde - cuidados nutricionais, alerta para o uso de camisinha, doação de sangue, prevenção de AIDS e Hepatite. Carnaval e Comércio - comercialização de acessórios e fantasias, instrumentos musicais, produtos carnavalescos e geração de trabalho e renda. $\mathrm{O}$ Carnaval e a Quaresma foram outra categoria necessária visto que mobilizou várias instâncias da sociedade - Bispo de Cruz Alta, Poder Público, Liga das Escolas de Samba e cidadãos, com posicionamentos diferentes a cerca do período de realização dos desfiles das escolas, que coincidia com o início da quaresma cristã.

A Categoria que mais aparece é Carnaval de Rua com 46 registros (38\%), depois vem Carnaval com 24 registros (20\%), seguido de Carnaval de Clube com 20 registros (17\%), Carnaval e Saúde com 17 registros (14\%), Carnaval e Comércio com 10 registros (8\%) e Carnaval e Quaresma com 04 registros (3\%), totalizando 121 registros entre matérias jornalísticas e publicitárias. A partir desses dados fica evidente que o Carnaval é pauta na mídia cruzaltense e a priori, o jornal está presente cumprindo sua função principal de informar a sociedade sobre os acontecimentos.

Em termos jornalísticos dos 94 registros, 40 são sobre o Carnaval de Rua, 21 sobre o Carnaval, 17 sobre o Carnaval e Saúde, 05 sobre o Carnaval de Clube, 08 sobre o Carnaval e Comércio e 03 sobre o Carnaval e Quaresma. Esses dados evidenciam o grau de importância que o jornal destina ao evento. O Carnaval de Rua e o Carnaval são os temas mais explorados pelos redatores do veículo. É importante ressaltar que o Carnaval é considerado uma festa muito importante na vida dos brasileiros, é sinônimo de alegria e 
descontração, em sua essência é cultura popular, folclore, tradição, celebração, espetáculo. O significado cultural do evento não foi encontrado em nenhuma matéria do jornal.

Com relação a publicidade foram apontados 27 registros, 14 sobre Carnaval e Clube, 08 Carnaval de Rua e 03 Carnaval e Quaresma e 02 Carnaval e Comércio. Esses números comprovam que o Carnaval não é muito explorado pelo comércio local e sim pelo espaço social que têm na vida da sociedade cruzaltense.

A terceira etapa da pesquisa buscou saber o espaço ocupado quanto a categorias comunicacionais. O jornalismo informativo predominou no registro dos fatos, apenas um artigo opinativo foi encontrado na amostra da pesquisa. Na área publicitária prevaleceram as matérias pagas com 18 registros e apenas 09 anúncios. Portanto o jornalismo se destacou em todos os meses analisados, ocupando um espaço maior $(77,6 \%)$ do que àquele destinado à publicidade $(22,4 \%)$.

A última etapa da pesquisa quantitativa procurou identificar as matérias com ilustração, fotografias são frequentemente utilizadas pelo veículo. Foram encontrados 66 registros de matérias constituídas por texto e foto, dessas 46 são coloridas e 20 nas cores pretas e brancas.

Em termos qualitativos a análise da cobertura carnavalesca procurou responder questões quanto aos eixos temáticos e estratégias comunicacionais.

No que se concerne aos eixos temáticos à maioria dos conteúdos das matérias tem enfoque tradicional do carnaval, refere-se à escolha da corte, concurso de fantasias e rainhas, desfile das escolas de samba, blocos de clubes e movimento do comércio. No entanto um fato inusitado criou um conflito entre as instâncias sociais envolvidas no evento. A data estipulada para o evento coincidiu com o período da quaresma.

Logo a proposta de realizar o carnaval em tempo de quaresma gerou polêmica entre a Liga das Escolas de Samba de Cruz Alta - LESCA e a igreja Católica. O Bispo Dom Frederico Heimler, em nome da Diocese de Cruz Alta, se posicionou contra a atitude da entidade e das escolas, em realizar a festa no início do período da quaresma cristã. A sociedade manifestou prós e contras, o prefeito Vilson Roberto, em nome do poder Público, intermediou o debate entre a LESCA e a igreja Católica e conseguiu entrar em acordo com as entidades, considerando a data oficial 24 de janeiro para o início dos festejos. Essa decisão ressalta que o carnaval de Cruz Alta, enquanto manifestação popular atende, sobretudo aos princípios ideológicos da religião católica, priorizando a tradição, a 
cultura e o respeito ao tempo sagrado da quaresma e, especialmente, resgatando a essência cristã da celebração.

Algumas matérias têm um ponto de vista inovador quando tratam assuntos referentes aos cuidados com a saúde no período do carnaval. Como já foi visto anteriormente os registros enfocam cuidados nutricionais, uso de camisinha, doação de sangue, prevenção de AIDS, Hepatite e acidentes. Esse tipo de abordagem tem a possibilidade de transformar o evento num momento contraditório, já que tem, por um lado, alegria, folia, entusiasmo e, por outro, abuso, risco de contaminação, acidente e morte, embora a parte favorável do evento predomine diante da desfavorável.

O carnaval de Cruz Alta é celebrado a partir de um ritual onde as pessoas querem aproveitar a folga para se divertir, abolir diferenças, trocar posições e uniformes, igualar os sentimentos, esquecer problemas, enfim, compartilhar momentos de felicidade e fantasia. Para DaMatta (1997, p. 75) essa fantasia permite a invenção e a troca de posições, "promove a passagem para outros lugares e espaços sociais", por isso o autor considera o carnaval como um "rito de inversão" onde a igualdade e desaparecimento de fronteiras são permitidos e todos os atores são protagonistas de uma história de amor. A paixão pelo carnaval de rua (cenário) tem lugar maior do que o de clube (personagem) e somente os excessos do acontecimento são motivos de reflexão, as demais são meramente informativos. Quanto à natureza da festa as estruturas aparecem com mais ênfase do que os elementos que os constituem.

Embora o carnaval cruzaltense tenha o âmbito regional a prioridade é para as noticias locais, não há menção alguma sobre a festa em outras regiões do Brasil. $\mathrm{O}$ presente é o que importa e o espaço público, onde pessoas de todas as classes sociais se unem para curtir a festa, mesmo que as distinções apareçam de forma clara nas fantasias e alegorias que os foliões apresentam, tem vantagens diante do privado. As minorias idosos e pessoas com necessidades especiais têm raríssimos espaços. Os principais atores sociais que compõem a festa são os integrantes das escolas de samba e dos blocos que contam com o apoio do Poder Público Municipal, Secretarias de Cultura, Turismo e Saúde, Polícias Militar, Civil e Rodoviária.

Quanto a estratégias comunicacionais predomina o jornalismo informativo e a persuasão é pouco utilizada na área publicitária. As matérias, em sua maioria, são relatadas de forma objetiva, clara e breve, características essas, da linguagem jornalística. A maioria dos anúncios usa apelo racional, como argumento de venda, apenas algumas matérias 
pagas possuem enfoque emocional, portanto a retórica que segundo Collins Papperback (1999, p. 707) "é a arte de usar fala ou escrita para persuadir ou influenciar" não faz parte das estratégias comunicacionais do veículo. Quanto à utilização de ilustrações os registros aparecem de forma articulada, a imagem confirma o fato, na maioria das vezes a figura que acompanha o texto, é uma foto legenda.

A seguir a mensuração das categorias e estratégias comunicacionais em percentual.

\section{Categorias comunicacionais: Jornalismo (77,6\%) - Publicidade $(22,4 \%)$}

\section{Eixos temáticos}

Tradição $83 \%$ - Inovação 17\%

Celebração: $80 \%$ ritos - $20 \%$ motivações

Simbologia: $70 \%$ cenários $-30 \%$ personagens

Natureza da festa $-85 \%$ estruturas $-15 \%$ elementos

Espaço/tempo

Territorialidade: 00\% Global - 00\% Nacional - 00\% Regional - 100\% Local

Temporalidade: 00\% Passado - 100\% Presente - 00\% Futuro

Público $70 \%$ - Privado - 30\%

Atores sociais: $20 \%$ Instituições - 10\% Classes - 40\% Comunidades - 30\% Pessoas

\section{Estratégias comunicacionais}

Informação $92 \%$ - Persuasão $08 \%$

Noticiário: 95\% Relatos - $05 \%$ Argumentos

Anúncios: 50\% Produtos/Serviço - 30\% Patrocinadores - 18\% Público-alvo

Texto Ilustração

Codificação: 98\% Linguagem - 02\% Retórica

Evidenciação: $98 \%$ Fotos - 02\% Gravuras

\section{Algumas considerações}

Ao final do estudo que teve como base a teoria da folkcomunicação de Luiz Beltrão, que propõe um estudo sobre a forma de comunicação dos grupos marginalizados sem o uso dos meios massivos, e mais precisamente de José Marques de Melo que a partir da mesma teoria busca identificar como a mídia massiva se apropria de elementos da cultura popular para noticiar a mesma, é possível identificar através da análise dos dados coletados que a cobertura que o jornal Diário Serrano faz do evento é insuficiente pelo grau de importância que o carnaval possui na vida da comunidade cruzaltense. 
O veículo estudado apenas informa sobre o evento, sem buscar se apropriar dos elementos culturais das comunidades carnavalescas, para assim se comunicar e servir de meio de comunicação para as mesmas, tão pouco contribui no sentido de valorizar a identidade cultural destas comunidades, abordando o trabalho social e cultural que se desenvolve espontaneamente entre os integrantes das escolas de samba.

Além disso, na mesma proporção em que o veículo analisado não atenta para estes aspectos projeta para a comunidade que desconhece o bastidor do carnaval, a idéia de um evento isolado, em que as escolas apresentam um espetáculo na avenida. E com isso de algum modo influencia na percepção das pessoas quanto à importância da comunidade carnavalesca na vida social e econômica daqueles que vivem anualmente no interior da agremiação.

É importante destacar que todo este bastidor das comunidades carnavalescas ainda é algo desconhecido, e que o meio de comunicação estudado não dá a devida visibilidade a esse trabalho muitas vezes abordando o tema carnaval como um período apenas de "festa" em um sentido pejorativo.

Entretanto no caso estudado, o evento não é apenas uma forma de manifestação da cultura popular, que age como um mecanismo de poder entre as comunidades, pelo sentimento de pertença que mobiliza e os compromete de forma a se dedicar e se doar para a o sucesso das escolas na avenida, mas, sobretudo, como uma forma de emancipação através do trabalho, da disciplina, do comprometimento e da responsabilidade.

Desta forma, reconhecer o papel da cultura popular, no fortalecimento das relações sociais, nas transformações dessas relações, na inclusão social, na construção de identidades e no crescimento pessoal e profissional é que nos permitem afirmar a sua importância, principalmente quando possibilitam ao povo a construção de espaços de participação, formas de expressão e representação simbólica de um grupo, que no conjunto da sociedade não teria esta visibilidade, como o que ocorre no carnaval de Cruz Alta.

\section{Referências bibliográficas}

DAMATTA, Roberto. O que faz o brasil, Brasil? Rio de Janeiro: Editora Rocco Ltda, 1997.

CARVALHO, Samanta Viana Castelo Branco Rocha. Metodologia folkcomunicacional: teoria e prática. In: DUARTE, Jorge; BARROS, Antônio. (org.) Métodos e técnicas de pesquisa em comunicação. São Paulo: Atlas, 2008. $2^{\mathrm{a}}$ Ed.

JORNAL DIÁRIO SERRANO. Disponível em: www.diarioserrano.com.br. Acesso em 15 de abril de 2009. 
MARCHIORI, Marlene. Cultura e comunicação organizacional: um olhar estratégico sobre a organização. São Caetano, SP: Difusão Editora, 2008.

MELO, José Marques de. Mídia e cultura popular: história, taxionomia e metodologia da Folkcomunicação. São Paulo: Paulus, 2008. (Coleção Comunicação).

NERY, Vanda Cunha Albieri. Samba no pé... Alegria na avenida: um estudo do carnaval de rua à luz da folkcomunicação. Trabalho apresentato ao NP 17 - Folkcomunicação, do V Encontro dos Núcleos de Pesquisa do Intercom. Disponível em: www.intercom.org.br/papers/nacionais/2005/resumos/R1183-1.pdf. Acesso em 15 de abril de 2009.

\footnotetext{
${ }^{\text {i }}$ Pesquisa desenvolvida para o projeto "Carnaval: palco de manifestação da cultura popular e de reafirmação identitária de um grupo", da Universidade de Cruz Alta - UNICRUZ.

${ }^{\text {ii }}$ Professora do Curso de Comunicação Social da UNICRUZ, mestranda do Programa de Pós-Graduação em Comunicação da Universidade Federal de Santa Maria - UFSM. E-mail: fabi@ comnet.com.br

iii Professora do curso de Relações Públicas - Ênfase em Produção Cultural da Universidade Federal do Pampa UNIPAMPA, doutoranda do Programa de Pós-Graduação em Extensão Rural da Universidade Federal de Santa Maria UFSM. E-.mail: marcelasilva@ unipampa.edu.br
} 